Case Report

\title{
Trismus: An unusual presentation following road accident
}

\author{
Jagdeep S. Thakur, C. G. S. Chauhan, Vijay K. Diwana, Dayal C. Chauhan \\ Department of Plastic and Reconstructive Surgery, I.G. Medical College, Shimla, India
}

Address for correspondence: Dr. Jagdeep S Thakur, Department of Plastic and Reconstructive Surgery, I.G. Medical College, Shimla, HP - 171 001, India. E-mail: anujagdeep@yahoo.co.in

\begin{abstract}
Trismus due to trauma usually follows road accidents leading to massive faciomaxillary injury. In the literature there is no report of a foreign body causing trismus following a road accident, this rare case is an exception. We present a case of isolated presentation of trismus following a road accident. This case report stresses on the thorough evaluation of patients presenting with trismus following a road accident.
\end{abstract}

\section{KEY WORDS}

Foreign body, trismus

rismus (Trismos: Greek word meaning grinding) is a condition with restricted mouth opening. Normal mouth opening, as measured by the anterior gap between the upper and lower incisors, including overbite, is 35-50 mm. ${ }^{[1]}$ The muscles of mastication are Temporalis, Masseter, Medial Pterygoid and Lateral Pterygoid. The mouth is opened by the Lateral Pterygoid and sometimes helped by the suprahyoid muscles (Digastric, Geniohyoid and Mylohyoid) during mouth opening against resistance. The temporomandibular joint is the only joint involved in the process of mouth opening. This temporomandibular joint is a ginglymo-arthrodial type of joint which is a combination of hinge and gliding type of joint. The restricted mouth opening can be due to either the involvement of this joint or pathology of muscles which are responsible for mouth opening. The aetiology of trismus can be, hence, divided as extra capsular or intra capsular. The causes in both include trauma, infection or malignancy. The patient usually complains of difficulty in opening the mouth or sometimes difficulty in eating, speech or pain which takes him or her to the otolaryngologist or dentist for consultation.

\section{CASE REPORT}

A 35-year-old male, conductor by profession, met with a vehicular accident. He presented with a complaint of trismus in the Emergency department [Figure 1]. On examination, he had a metal foreign body impacted in the area of the temporomandibular (TM) joint on the left side [Figure 2], with no other sign of injury on the body. X-ray skull, both lateral and anteroposterior views were done and showed a metallic foreign body with three prongs [Figure 3] which were impacted in the temporal bone, TM joint and ascending ramus of the mandible respectively. The haemogram and LFT/RFT were found to be normal. Patient was taken up for extraction of this foreign body under general anaesthesia. The foreign body was simply pulled from the site. The wound was explored for any bony fracture, vascular, nerve or muscular injury and was found to be normal. This foreign body was a 'trishool' also known as a trident [Figure 4]. This is a weapon used in Hindu mythology, and was fixed as a decoration on the bonnet of the truck, in which the patient met with an accident. After the extraction of this foreign body, the 


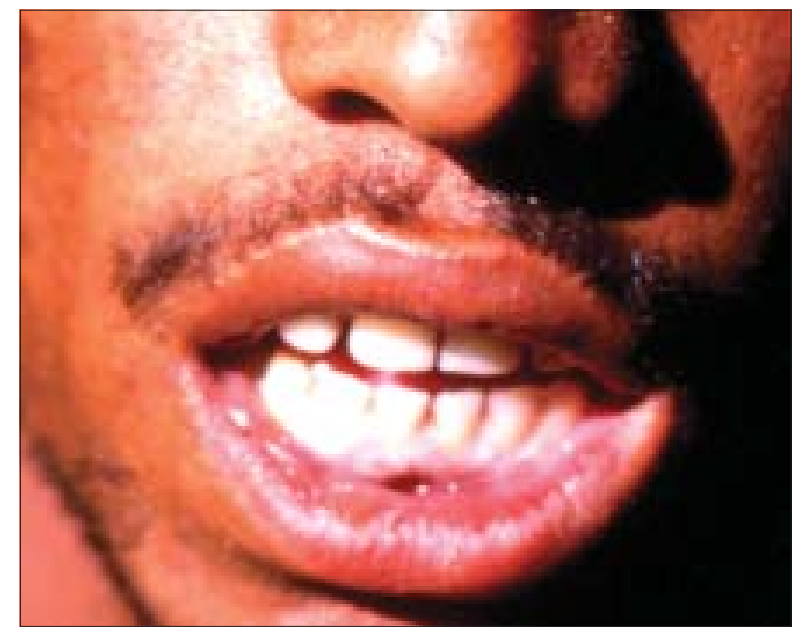

Figure 1: Photograph of the patient showing trismus

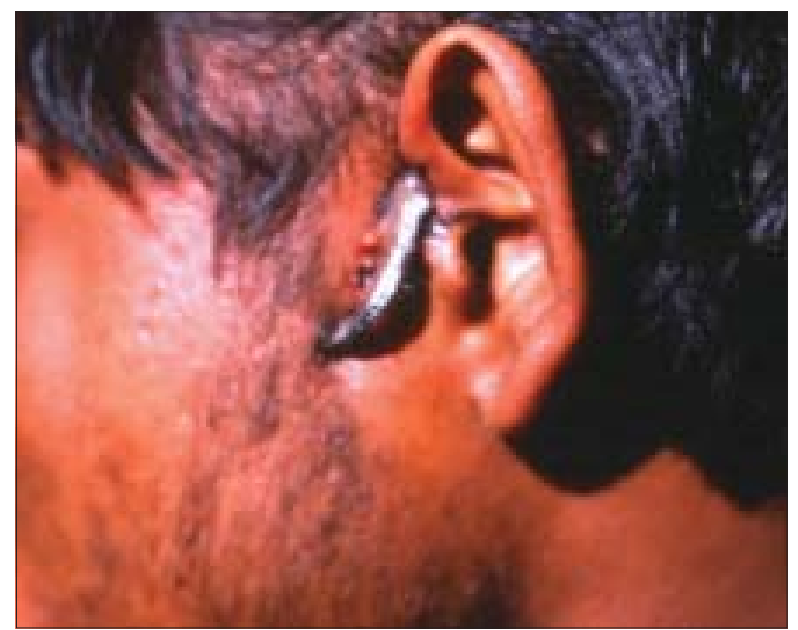

Figure 2: Photograph of the patient showing foreign body lodged in the temporomandibular area

trismus of the patient improved immediately. His mouth opening was adequate postoperatively. In the follow-up, the patient did not have any sequel to this foreign body trauma in the temporomandibular joint which could have lead to the ankylosis of the joint.

\section{DISCUSSION}

Trismus due to trauma usually follows road accidents leading to massive faciomaxillary injury. Penetrating foreign bodies in the head and neck region are uncommon. ${ }^{[2]}$ There are a number of reports of trismus due to a foreign body lodging in the infra temporal fossa in the English language literature. ${ }^{[2-5]}$ Lacy et al. ${ }^{[2]}$ reported a migrating foreign body causing trismus after 16 years and stressed for thorough examination of patient following foreign body injury.

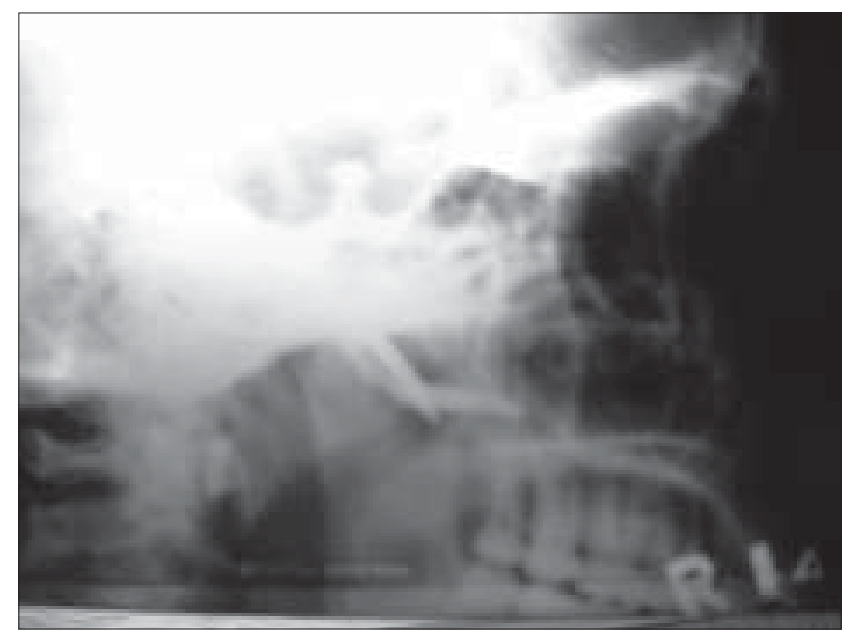

Figure 3: X-ray of the skull lateral oblique view showing metallic foriegn body

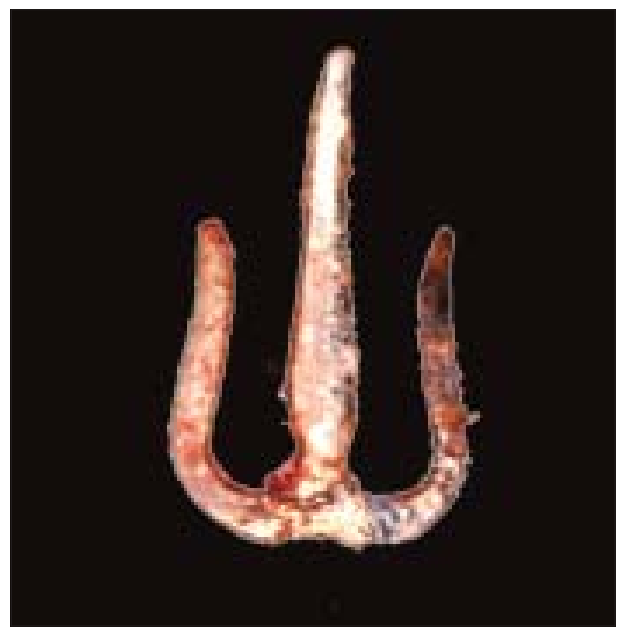

Figure 4: Photograph of the removed foreign body 'Trishool'

Isolated trismus due to foreign body lodging in the temporomandibular joint following road accident is not reported in the English language literature (Medline search). In this rare case, there was no other facial or body trauma except the foreign body lodging in the area of the temporomandibular joint and acting as an external fixator. One of the prongs of the 'trishool' was impacted on the ramus of mandible, the second was impacted in the temporal bone and the central limb was in the joint area.

\section{CONCLUSION}

Although trismus following road accidents is usually due to the fracture of mandible, foreign body lodging in the temporomandibular joint following road accident has not been reported. In this rare case the foreign body was 
quite big in size but this is an example to keep in mind the possibility of a foreign body as the cause of trismus if no other cause is found on clinical examination. This type of foreign bodies should be removed as early as possible to avoid foreign body reaction and ankylosis of the temporomandibular joint subsequently.

\section{REFERENCES}

1. Luyk NH, Steinberg B. Etiology and diagnosis of clinically evident jaw trismus. Aust Dent J 1990;35:523-9.
2. Lacy PD, Timon $\mathrm{Cl}$, Ryan $\mathrm{CD}$, Donnelly MP, McShane DP. Migrating foreign body: A new cause of trismus. J Laryngol Otol 1995;109:990-1.

3. English GM, Hemenway WG. Infratemporal fossa foreign body. JAMA 1968;204:631-3.

4. Malhotra C, Arora MM, Mehra YN. An unusual foreign body in the nose. J Laryngol Otol 1971;84:539-40.

5. Maisels DO, Priestland HA. Plastic trismus: A difficult diagnostic problem. Br J Plast Surg 1973;26:223-6.

Source of Support: Nil, Conflict of Interest: None declared.

\section{Author Help: Sending a revised article}

1) Include the referees' remarks and point to point clarification to those remarks at the beginning in the revised article file itself. In addition, mark the changes as underlined or coloured text in the article. Please include in a single file

a. referees' comments

b. point to point clarifications on the comments

c. revised article with text highlighting the changes done

2) Include the original comments of the review ers/editor with point to point reply at the beginning of the article in the 'Article File'. To ensure that the reviewer can assess the revised paper in timely fashion, please reply to the comments of the referees/editors in the following manner.

- $\quad$ There is no data on follow -up of these patients.

Authors' Reply: The follow up of patients have been included in the results section [Page 3, para 2]

- $\quad$ Authors should highlight the relation of complication to duration of diabetes.

Authors' Reply: The complications as seen in our study group has been included in the results section [Page 4, Table] 